logos_i_ethos_2016_1_(41),s. 57-72

DOI: http://dx.doi.org/10.15633/lie.1793

Władysław Zuziak

Universidad Pontificia de Juan Pablo II de Cracovia

\title{
Condenados a la solidaridad. Pensamiento moral de Józef Tischner
}

En el presente artículo se pone de relieve el papel tan importante que desempeñó el profesor Josef Tischner que implicaba participar en el movimiento a través de su reflexión fenomenológica, que incidió iluminando el proceso de creación, aunque también criticándolo, según se hicieran evidentes algunos fallos o hiciera falta resaltarlos para lograr corregirlos. Por otra parte, se señalan las diversas etapas que sufrió el proceso de creación y construcción de Solidarność, esto es, el mo-

Władysław Zuziak - rev., prof., catedrático de ética y filosofía en la Universidad Pontificia de Juan Pablo II de Cracovia. Publicaciones i.e. Społeczne perspektywy etyki [Perspectivas sociales de la ética] (Kraków 2006) y Aksjologia Louisa Lavelle'a wobec ponowoczesnego kryzysu wartości [La axiología de Louis Lavelle frente a la crisis postmoderna de los valores (Kraków 2012). Miembro de la ESSSAT (Sociedad Europea para el estudio de la Ciencia y la Teología), la FUCE (Federación de Universidades Católicas Europeas) y la PTF (Sociedad Filosófica Polaca). Campos de investigación: filosofía del hombre, ética, personalismo, axiología y filosofía francesa del siglo XX. vimiento social del que se ha dicho tomo posición intelectual J. Tischner. También lo que se puede lograr en el orden ético y político de una sociedad que necesita liberarse de la opresión, pero que al mismo tiempo está encerrada en esa miseria. Finalmente se intenta exponer el valor ético de todo este movimiento y sus participantes, en orden a explicar ciertas categorías morales fundamentales en el contexto de la solidaridad más allá del caso polaco, resaltando la necesidad que tiene el mundo de abrirse al pensamiento y a la solidaridad. 


\section{Pensamiento de J. Tischner en el contexto social e histórico de la solidaridad}

Josef Tischner fue un testigo privilegiado de los acontecimientos que llevaron al nacimiento de Solidarność y al fin de la era comunista en Polonia. Al mismo tiempo, no pudo menos que mirar con ojos críticos la evolución posterior. Participóactivamente en los encuentros que poco a poco estructuraban este nuevo movimiento, predicando, celebrando los sacramentos y publicandotextos que podríamos denominar polémicos. En sus discursos intentó mostrar tanto las posibilidades como el peligro de este proceso de emancipaciónsocial de un pensamiento impuesto por un régimen totalitario.

El problema más importante, y a la vez más difícil de resolver fue, en su opinión, el que trataba de la necesidad de conciliar una verdadera liberación de todos los participantes en esta transición, con la conservación, a un mismo tiempo, del sentido de comunidad. Antes de esta manifestación de Solidarność, Tischner estudió la filosofía del diálogo de Levinas y reflexionó sobre las condicionesdel drama de existir en los sujetos particulares que quieren realizarse en las trágicas circunstancias del proceso histórico que han sido superadas. Al mismo tiempo indicó que una manera en que podrían resolverse estos problemas era, precisamente, la apertura a y el encuentro de otro ser humano. En 1978, sin convicción pero con esperanza escribió: "no existe ninguna necesidad de encuentro alguno. Es verdad que encontramos a Dios y a las personas, pero todo esto sucede accidentalmente. El acontecimiento de un encuentro es un don gratuito en el tiempo que sobrepasa nuestras esperanzas y nuestra imaginación: 'El Espíritu sopla donde quiere'. Desde cada perspectiva se nos manifiesta la libertad"1. Dos años más tarde, repentinamente hubo una explosión social, que no fue una explosión iracunda, como sí una aspiración de la sociedad que estaba antes ahogada. Tischner estaba convencido de que este era el encuentro sobre el que había escrito.

1 J. Tischner, Myślenie według wartości [Un pensamiento de acuerdo a los valores], Kraków 1982, p. 496. 
Solo que en este encuentro, que desbordaba sus esperanzas e imaginación, participaban millones de personas liberadas de las ilusiones y el temor previos, multitudes que solamente deseaban vivir con dignidad y sinceridad en un mundo dirigido con justicia. Durante los primeros meses de esta inversión solidaria parecía, no solamente a Tischner, que ante sus ojos se realizaba el sueño más bello de un profesor-moralista; que se era testigo de la creación de un ideal de sociedad, en la cual la divisa primordial era un imperativo bíblico: "Ayúdense mutuamente a llevar las cargas"'.

Hay, como se sabe, dos tipos de sucesos fundamentales para el desarrollo social: la cooperación de las personas ylos conflictos que inspiran a buscar soluciones. Se sabe también también que lo bueno y duradero exige un esfuerzo moral constante.

En la Polonia de 1980 todoslos participantes del movimiento "Solidarność" habían oído e identificado en él sus propias angustias y habían encontrado en él un significado que les era afín. En comparación con la gris realidad socialista, cualquier otra realidad distinta de esta, oficialmente decretada e impuesta, les parecía atractiva. Más aún en cuanto se trataba de una idea infundida en la conciencia social de los obreros, secundados por los intelectuales, ya fueran artistas, pensadores o científicos. Allí cada uno pudo reconocer algún elemento de sus propios anhelos y por lo tanto, otorgarle su propio significado a la idea que surgía, al parecer "de la nada". "Solidarność" se caracterizó sobre todo por su polifonía, pero también por la pluralidad de significados. Cada uno la entendía según su parecer - a semejanza de una pareja que se declara amor, pero que cada uno de ellos lo entiende y vive a su manera. “ ¿Cuál es el resultado de esta pluralidad en el mismo punto de salida? - preguntaba Tischner años después Es fácil de prever: tal situación tuvo que acabar originando sospechas, acusaciones, divisiones y peleas en el seno de la antigua 'Solidarność"’3.

Ga 6, 3.

3 J. Tischner, Cierpkie winogrona i chytrość rozumu [Las uvas agrías y la malicia de la razón], “Znak” 1998 nr 8 (519), p. 37. 
Al parecer toda la sociedad polaca necesitabacooperación para su desarrollo económico y social. Hacía falta vivir y desarrollarse dentro de una comunidad en ese espíritu de la solidaridad; construirla apoyándose en la tradición común de "Solidarność" tras la caída del comunismo en la Polonia de 1989. Al fin, es un hecho que hubo planes de creación de una sociedad solidaria que, empero, no se llevaron a cabo en los primeros años del cambio de régimen. Desgraciadamente, resulta una tarea particularmente difícil en una sociedad basada en el principio de neutralidad, en cuya mentalidad no existe una jerarquía de valores especial, sino que todas son igualmente dudosas. Todo debate, todo intento de establecer un consenso ha de llevar a fijar un compromiso entre los intereses de todas las partes. De esta manera, la libertad queda relegada a un nivel instrumental, mientras "la preocupación por la libertad se convierte en 'una preocupación por el poder' - el ansia de la 'voluntad de poder"'4. La libertad entendida como un deseo de voluntad de poder nos encamina hacia un mundo en el cual lo único que cuenta es la fuerza y el poder. En tal mundo, lo único que importa es la libertad de los más poderosos, de modo que es no tanto un poder sino violencia dirigida contra los demás.

En estas condiciones, la realidad social no tiene nada que ver con la solidaridad: es "un colectivo de personas que de manera egoísta intentan satisfacer sus intereses particulares. Todo lo que actualmente se relaciona con la confianza, responsabilidad y solidaridad es tratado cada vez más" - según las palabras de P. Sztompka - "como una necesidad de

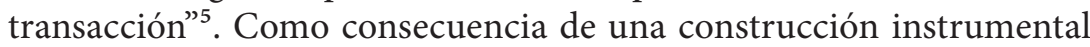
y "transaccional" de la comunidad, el individuo deja de percibirse como persona ${ }^{6}$ y se siente cada vez más aislado. Expresándolo con las mismas

4 J. Tischner, Spór o istnienie człowieka [Controversia sobre la existencia del hombre], Kraków 1998, p. 294.

5 P. Sztompka, Zaufanie. Fundamenty społeczeństwa [Confianza. Los fundamentos de la sociedad], Kraków 2007, p. 12.

6 "La historia de la esperanza y del sentido de dignidad del hombre son inseparables. En cierta etapa el individuo ya sabe: 'no pueden matar el alma'. En el hombre existen valores de los cuales nadie le puede privar, si el hombre no se priva de ellos él mismo" (J. Tischner, Ludzie z kryjówek [Los hombres de los escondites], [en:] J. Tischner, Myślenie według wartości, Kraków 1993, p. 455). 
palabras de Juan Pablo II, el individuo, en vez de "participar activamente en una comunidad auténtica y solidaria, cae en un aislamiento más profundo dentro de un complejo sistema de relaciones, determinadas por la rivalidad implacable y el apartamiento, en el cual se trata al individuo como un medio y no como un fin en sí mismo"7.

En tal mundo, el desamparo, las angustias y las frustraciones despiertan ira y originan tensiones sociales que no solo se convierten en la causa de enfermedades de la civilización (cuando la fuente es interiorizada), sino también llevan a una escalada de violencia. Los individuos que habían salido de sus escondites tras un breve despertar moral, pierden la esperanza de mejorar la realidad y vuelven a sus escondites y a sus enfermizas visiones del mundo que crecen y se alimentan de sus miedos arraigados.

Este mecanismo, que hizo que mucha gente regresara a sus escondites, fue muy visible en los primeros años de la transición polaca. Quedarse maravillado por la libertad negativa, la "libertad de", iba a la par con la gradual pérdida de esperanza que había de un cambio moral en una sociedad que se estaba liberando de una opresión para caer en otra.

\section{La salida de los escondites}

Al observar los cambios de mentalidad en Polonia, Tischner describía el proceso de la desolidarización de la sociedad y su negación a realizar los valores comunes: "La libertad del individuo y el espacio de la esperanza están estrechamente vinculados. Cuando cambia la libertad, cambia el espacio de la esperanza, y con él cambia también el ser humano. Así puede uno construir su escondite. El escondite supone el espacio de una libertad temerosa, preocupada por protegerse a sí misma. El espacio abierto de la esperanza equivale al espacio de una libertad preocupada por realizar los valores [...]. Los problemas con la esperanza nos encierran al mundo; el individuo huye de los demás y se aísla en su propio mundo"s. La gente,

Cf. Juan Pablo II, Centesimus Annus, n. 41.

8 J. Tischner, Ludzie z kryjówek [Los hombres de los escondites], [en:] J. Tischner, Myślenie według wartości [Un pensamiento de acuerdo a los valores], Kraków 1993, p. 439-440. 
al no poder realizar los valores que le parecen importantes dentro de la comunidad, regresa a sus escondites - allí puede cultivar sus anhelos más íntimos protegiéndolos contra una mirada desdeñosa e irónica del otro.

Al perder la esperanza, los individuos empiezan a sentir cada vez más miedo de los demás. El otro es "siempre este en quien no se puede confiar. Hay que mantenerlo a una distancia segura: no demasiado cerca, ya que es lo que amenaza con hacernos daño, y no demasiado lejos, ya que es lo que puede conducirnos al aislamiento" ". El otro constituye un enemigo, pues uno debe evitarlo o vencerlo: "para un individuo del escondite, la apropiación es una forma elemental de domesticar al otro y al mundo. La organización del espacio posee claramente un matiz de angustia"10. Un individuo atormentado está buscando un escondite donde ampararse. La necesidad de seguridad compite con la necesidad de libertad, y "dependiendo de los valores elegidos, en su vida el individuo optará por un camino de creación, o se quedará en la seguridad de su escondite" ${ }^{11}$. La mayoría de la gente elige la segunda opción.

La forma de escondite más común es la máscara, la cual uno se pone no solo para proteger su propio mundo, sino también para dominar a los demás. La máscara, como escribía Tischner, "no es una cubierta ni una cara. La cubierta solamente tapa la cara, la máscara miente. El miedo es el origen principal de la máscara [...]. La máscara es el aspecto del hombre visto a través de una ventana del escondite"12. Ya no se trata de ser plenamente uno mismo, de desarrollarse y colaborar, sino de esconderse.

El mundo de la gente enmascarada, el mundo de la gente de los escondites que procura apilar un abultado botín y sentirse segura al imponer su voluntad a todo aquello que la rodea;es un mundo donde vivimos, donde cada uno lucha con el otro en varios niveles: por el trabajo, por

9 J. Tischner, Ludzie z kryjówek [Los hombres de los escondites], [en:] J. Tischner, Myślenie według wartości, Kraków 1993, p. 445.

10 J. Tischner, Ludzie z kryjówek [Los hombres de los escondites], [en:] J. Tischner, Myślenie według wartości, op.cit., p. 441.

11 J. Tischner, Myślenie według wartości [Un pensamiento de acuerdo a los valores], op. cit., p. 417.

12 J. Tischner, Filozofia dramatu [Filosofía del drama], Kraków 1998, p. 66. 
las ganancias, por un coche mejor, por los privilegios, por la riqueza, por la supervivencia... Esta guerra no conoce piedad para los débiles, los vencidos o los adversarios. La lógica de la lucha excluye cualquier compasión. La lealtad y la cooperación, admitidas únicamente entre los aliados y desde luego en la medida necesaria para conseguir un fin, quedan abolidas en el momento de dividir el botín. Es un mundo del mal construido, compartido y percibido por cada uno. Ni la mejor ley es capaz de proteger a los débiles contra la violencia de los más fuertes.

La sociedad creada por la gente de los escondites no solo no se encuentra capacitada para constituir una comunidad solidaria, sino que ni siquiera sabe funcionar como un mecanismo eficiente. Tal sociedad se rige por un caos axiológico que impide la comunicación y el entendimiento. No hay manera de resolver los problemas crecientes. No se sabe tampoco quién y por qué haría el primer paso. Toda iniciativa puede ser interpretada como un indicio de debilidad o traición.

\section{Es posible salir del escondite}

Tanto "Solidarnośćc" como muchas otras situaciones históricas demuestran que es posible, aunque esa posibilidad acontece en unas condiciones específicas, bajo la tensión a la que están sometidos los individuos en los momentos de cambios históricos, y no suele durar mucho. Según Tischner, el individuo consigue salir de su escondite para siempre solo cuando recupera la esperanza y el sentido de su dignidad. Sentir la dignidad junto a la auténtica autoestima nos inspira a tener fe en nuestras propias fuerzas, nuestra propia libre capacidad y nos deja confiar en los demás. No obstante, no es fácil recuperar la esperanza tras haber sido herido. Es aquí donde se libra una auténtica lucha entre el bien y el mal. La voz del mal persuade: "En el jardín de Edén la serpiente me ha puesto a prueba, así que no confíen en mí. La tierra me ha ofrecido cardos y espinas, así que vivo en una tierra negada [...]. Estoy condenado a la vida, como un traidor"13. Pues todo lo que me toca es consecuencia de 
la traición. Y aquí estamos a un pequeño paso de constatar que todos estamos condenados y traicionados, y por ende destinados a traicionar.

Parece ser una situación sin salida. Si el otro es mi contrincante, la tierra se convierte en un campo de escondites. ¿Cómo podemos, entonces, convencer a todos los traicionados, que han experimentado el mal y han respondido con el mal, que el otro es nuestro prójimo y que la tierra puede ser un sitio apto para habitar?

Aunque parece improbable, ocurre en el mundo humano que "lo imposible acontece. La esperanza supera la desesperación"14. Para que lo imposible se haga real tiene que darse un encuentro. Tischner opina que "en el encuentro presenciamos directamente lo trágico del ser, el encuentro abre un horizonte agatológico y axiológico de la existencia. El encuentro supone un acontecimiento y como acontecimiento es a posteriori: empieza con la experiencia. Asimismo, el encuentro es posible gracias a un a priori ideal que controla su transcurso desde una posición oculta y es anterior al encuentro" ${ }^{15}$. El encuentro, siendo uno de los conceptos más importantes en la filosofía de Tischner, constituye "una fuente elemental de todas las experiencias axiológicas, incluida la experiencia de pensar"16.

El espacio donde se produce este encuentro es un escenario de nuestro propio drama. Todo lo que hemos vivido y experimentado tiene un papel importante en el momento del encuentro. Nuestras experiencias nos exigen mirar a través de la perspectiva axiológica. El drama de la existencia humana transcurre en el horizonte del bien y el mal. Arrastramos detrás de nosotros tanto el lastre común del mal que hemos vivido como también el bien que hemos experimentado juntos, a veces solo en breves momentos; sin embargo a menudo suficientemente importantes como para avivar la esperanza. Tenemos los mismos deseos que se manifiestan en las jerarquías de los valores preferidos. No se trata únicamente del

\footnotetext{
14 J. Tischner, Spór o istnienie człowieka [Controversia sobre la existencia del hombre], op. cit., p. 286.

15 J. Tischner, Myślenie według wartości [Un pensamiento de acuerdo a los valores], op. cit., p. $495-496$.

16 J. Tischner, Myślenie według wartości [Un pensamiento de acuerdo a los valores], op. cit., p. 486.
} 
peso de las experiencias, sino una especie de riqueza - un depósito de vivencias comunes, un material para entenderse tanto a sí mismo como al otro. Si comprendemos todo eso y nos esforzamos en buscar el punto de vista común, podremos "ascender por encima de nosotros mismos" y percatarnos de que todos juntos seguimos "encadenados"; es decir, que no conseguiremos liberarnos de esta opresión sin ayudarnos mutuamente ${ }^{17}$, y que hacer este esfuerzo común está arraigado profundamente en nuestro ser y reclama manifestarse.

Huelga notar aquí que todos los análisis del fenómeno de "Solidarność", al subrayar su importancia para la historia, olvidan un aspecto fundamental - que este fenómeno ocurrió espontáneamente. Este anhelo salió a la luz a pesar de los impedimentos del destino y las construcciones absurdas del sistema, y manifestó una necesidad humana importante - la necesidad de reciprocidad. ${ }^{18}$.

"Solidarność" demostró lo fuerte que es "el deseo más profundo del ser humano - el deseo de ser uno mismo" ${ }^{19}$. Ser uno mismo equivale a ser libre y poder desarrollarse. Hasta que no soñamos, hasta que no deseamos lograr algo, no podemos ser libres. El individuo puede elegir entre el bien y el mal, porque vive y se "constituye a sí mismo en el horizonte del bien y el mal, de los valores y antivalores, y en este camino se convierte en sí mismo" ${ }^{20}$. Nos constituimos a nosotros mismos construyendo un nuevo espacio social para nuestras aspiraciones y percibiendo que nuestra libertad requiere la libertad de los demás ${ }^{21}$. Esta es la siguiente lección que nos brinda la historia: el individuo por sí mismo no está capacitado

\footnotetext{
17 J. Tischner, Myślenie według wartości [Un pensamiento de acuerdo a los valores], op. cit., p. 495.

18 J. Tischner, Filozofia dramatu [Filosofía del drama], op. cit., p. 290: "descubrimos tres campos semánticos elementales dentro de los cuales se desarrolla y concretiza la presencia del hombre para el hombre: el campo de la reciprocidad, el campo de la oposición y el campo del gobierno".

19 J. Tischner, Myślenie według wartości [Un pensamiento de acuerdo a los valores], op. cit., p. 372 .

20 J. Tischner, Wybrane problemy filozofii człowieka [Algunos problemas de la filosofia del hombre], Kraków 1985, p. 6.

${ }_{21} \mathrm{~J}$. Tischner, Ksiądz na manowcach [Un sacerdote que yerra en un desierto], Kraków 1999, p. 274.
} 
para superar la tensión de los condicionamientos que le empuja hacia el mal y lo enreda en 'la lógica de venganza'. El individuo por sí mismo no es capaz de lanzarse a la libertad verdadera entendida como un modo de existencia del bien. Sin ayuda se pierde en la mentira y el mal, y va caminando hacia una tragedia inevitable. El individuo por sí mismo es débil, indeciso, lleno de defectos, y de ahí salen sus complejos. La soledad es causa de desesperación, depresión, frustración, sentido de culpabilidad y resentimientos. Un individuo solitario es susceptible de manipulación y se deja embaucar por todo tipo de ilusiones. No tiene posibilidad de un desarrollo auténtico para realizar los valores que le son afines. Está condenado a una vida según los guiones que le brindan los ideólogos, expertos de la ingeniería social y todo tipo de manipuladores. En la solitud no existen los criterios para diferenciar los valores reales, auténticos e importantes de los ilusorios. Cualquier visión de uno mismo y del mundo, incluso la más absurda, puede aparecer, dado que no existe la posibilidad alguna de verificar nuestras percepciones. La solitud es como una especie de encarcelamiento del cual uno no es capaz de liberarse por su propia cuenta, en el cual estamos condenados al mal de inercia, al abandono y destrucción del valor más preciado que nos han dado el valor de nosotros mismos. El único recurso del que disponemos para salir de esta situación tramposa consiste en abrirnos al otro, lo cual es posible solo si tenemos fe en nosotros mismos.

\section{Condenados a la solidaridad}

Nuestros valores, que muchos de nosotros vergonzosamente ocultamos en "los escondites", reclaman a otros individuos para ser confrontados con diferentes puntos de vista, preferencias y jerarquías de valores. Al percibir que, a pesar de las diferencias, los demás toman decisiones recurriendo a los mismos valores que nosotros, aunque articulados o jerarquizados de otra manera, nos abrimos a estas jerarquías y distintas formas de realizarlas. Aprendemos a contemplar nuestros propios valores y logros con cierta distancia [o: con distancia], distinguiendo no solo lo valioso, sino también los errores cometidos. 'En los ojos del 'otro' uno 
se descubre a sí mismo - su valor y la dignidad de su cultura. Entonces el 'otro' deja de ser un 'extraño' a quien hay que vencer, sino que se convierte en parte de su propia identidad, su propia 'sustancia ética'. Desde luego, para que los demás acepten estos valores, ya tienen que serlo con anterioridad. El individuo que no se esfuerza por ser valor ni tampoco 'portador de valores', en realidad se condena a sí mismo a 'la aniquilación"'22. Los que han olvidado su propio valor o no lo sienten, los 'aniquilados', hacen que la sociedad decaiga y desperdicie su potencial. Se requiere pues un esfuerzo común y un apoyo mutuo en la tarea de ser mejores; hay que compartir no sólo las cargas, sino también las alegrías, los hallazgos y los logros. El bien, en mayor grado que el mal, está vinculado a la alegría - y uno puede compartir esta alegría que surge cuando hace el bien. Y la puede compartir también con 'el enemigo'. Huelga notar que las personas que conocen su propio valor no son tan desconfiadas y temerosas, les resulta más fácil ‘solidarizar' el mundo con ellas mismas, no les cuesta tomar decisiones incluso menos beneficiosas para ellas, pero más provechosas para el bien común.

El mal nos engaña y corrompe en el camino hacia el bien, pero ¿qué es el mal? Es una deficiencia, una carencia, un error... ¿ Un ente real, que se está constituyendo como sucede con el hombre, puede perderse al afrontarse con "la nada"? - escribía Tischner. El mal, como los conflictos, es un elemento inseparable e imprescindible de la vida social. Como observó el gran existencialista francés L. Lavelle: "El bien es realmente solidario con el mal, ya que no se deja definir de otra manera sino como un mal superado"23. Se necesita el mal para poder reconocer el bien y para que podamos, al superar el mal, realizar este bien. "Existir realmente significa concebir el bien a partir de la nada envolvente del mal" 24 - y es tal vez el reto más heroico y excelso que afronta la humanidad.

\footnotetext{
22 J. Tischner, Ksiądz na manowcach [Un sacerdote que yerra en un desierto], op. cit., p. 208.

23 L. Lavelle, Traité de valeurs, t. 1, Paris 1951, p. 131.

24 J. Tischner, Filozofia człowieka dla duszpasterzy i artystów [La filosofía del hombre por los sacerdotes y artistas], Kraków 1991, p. 121.
} 
En el pensamiento ético de Tischner, la libertad constituye la esencia de la humanidad. Invariablemente, a pesar de "las desfavorables circunstancias" o "los condicionamientos negativos", podemos querer o no querer, o sea, podemos elegir: "En la vida debemos muchas cosas. Sin embargo, no tenemos que hacer el mal. Y si aún alguna fuerza, algún miedo, nos compele a hacer el mal, no puede forzarnos a persistir en este propósito"25. Incluso si cometemos un error y perpetramos un mal, mientras estemos vivos siempre podremos intentar vivir de una mejor manera. Tal como advirtió F. von Hayek: "No podremos ganar sabiduría en tanto no comprendamos que mucho de lo que hicimos fueron verdaderas locuras. Para construir un mundo mejor, hemos de tener el valor de comenzar de nuevo, aunque esto signifique reculer pour mieux sauter ['coger impulso para dar el puntapié'] [...]. Si hemos fracasado en el primer intento de crear un mundo de hombres libres, tenemos que intentarlo de nuevo" 26 .

Probablemente no hemos ganado aún suficiente sabiduría para crear un mundo justo, donde la solidaridad de unos no provoque la exclusión de otros. No sabemos cómo conciliar la necesidad de libertad y la de seguridad, la necesidad del desarrollo individual y la de creación de un bien común, ni cómo establecer una realidad humana en la cual la responsabilidad de sus propios actos y del bien de los demás sea el rasgo principal del carácter de una gente honrada, íntegra, abierta, sabia. Aún no existe tal mundo, pero no por eso debemos dejar de intentarlo - antiguamente los humanos no exploraban las profundidades, ni volaban al espacio. En los tiempos de Leonardo da Vinci no había recursos técnicos para construir máquinas voladoras, sin embargo, con el tiempo, las posibilidades técnicas evolucionaron a tal punto que hoy en día podemos realizar las aspiraciones humanas que anteriormente parecían imposibles. Asimismo, también la conciencia moral de las sociedades se está desarrollando. Las

25 J. Tischner, Pomoc w rachunku sumienia [Una guía para el examen de la conciencia], Kraków 2000, p. 42-43.

26 F. A. von Hayek, Droga do zniewolenia [Camino de servidumbre], tłum. K. Gurba, L. Klyszcz, J. Margański, D. Rodziewicz, Kraków 1996, p. 241-242. 
intuiciones "ecológicas" de San Francisco de Asís, que durante siglos no consiguieron ser comprendidas en la antropocéntrica cultura humana, hoy constituyen los fundamentos de la sensibilidad moral del hombre contemporáneo.

"Solidarność, la Revolución Francesa y muchos otros arrebatos morales que transcurrieron a lo largo de los siglos en nuestra cultura, manifiestan el mismo deseo de vivir en un mundo donde se respete la dignidad humana, y donde todos los - inevitables - conflictos se resuelven respetándola. Aún no hemos logrado crear un mundo así, pero no debemos dejar de intentarlo, especialmente porque la realidad actual resulta tan insatisfactoria que ya nos damos cuenta de la necesidad de un gran cambio. Las crisis que se perfilan en todos los ramos de la actividad humana evidencian que los modelos previos del desarrollo se han consumido.

Sin embargo, antes de que acontezcan nuevos cambios y se dé una nueva oportunidad para mejorar el mundo, nos espera un trabajo arduo que requiere paciencia. Tenemos que mostrar las grietas a través de las cuales irrumpen los rayos de la esperanza. Tenemos que mostrarle al hombre contemporáneo las posibilidades de recuperar la fe en sí mismo y en el otro, en su propia capacidad, y hacerle ver que somos capaces de concebir un mundo más amigable para nosotros mismos y las futuras generaciones. Según las palabras de la filósofa Chantal Millon Delsol, "tenemos que reconstruir convicciones (políticas, religiosas) y proyectos comunes, que les otorguen un carácter concreto, si no queremos que la solidaridad se limite exclusivamente a una simple división material del capital, lo cual es tanto necesario como insuficiente"27. Podemos llevarlo al cabo únicamente restaurando, despacio y con paciencia, la confianza mutua de todos los miembros de la sociedad. Lo cual no se deja hacer con métodos políticos, no se deja decretar, ni garantizar a través de las mejores medidas legislativas. Se requiere, en cambio, un nuevo proyecto de renovación, a largo plazo y con base social, gracias al cual la sociedad se transforme en una comunidad solidaria y democrática.

27 Ch. Millon-Delsol, Solidarność zakorzeniona [Una Solidaridad enraizada], “Znak” 2000 nr 543, p. 58. 
La Iglesia puede tener aquí un papel importante. Pero no llamando a la unidad desde los púlpitos, o indicando los únicos modelos de conducta que han de seguirse, sino iniciando acciones comunes en las comunidades locales e integrando a la gente en la realización de unos objetivos concretos. En una comunidad pequeña "no existe judío, ni pagano", todos se conocen, todos son "únicamente" vecinos, seres humanos. En tal comunidad cada acción ejerce un efecto concreto, cada error cometido acarrea un sufrimiento concreto, mientras cada objetivo realizado conjuntamente supone una razón concreta para enorgullecerse y constatar: nosotros lo hicimos. La acción común es, como observó Platón, la mejor manera para que "los ciudadanos puedan $[. .$.$] trabar amistades y cono-$ cerse, ya que no existe un bien mayor para un país que el que la gente se conozca" ${ }^{28}$. Sólo la acción común permitirá restaurar el sentido de dignidad y confianza, seguido por la solidaridad dentro de la cual cada ciudadano se sentirá útil y responsable de la vida comunitaria.

\section{Conclusiones}

Para concluir, pensamos que la solidaridad universal existirá siempre en los tratados de los filósofos o en las obras de los santos. En la realidad social, se materializa únicamente en las relaciones interpersonales, en unas situaciones concretas. Puede perfilarse como una solidaridad grupal, una solidaridad en la protesta contra algo y como una solidaridad en la búsqueda de la persecución de un objetivo común. La solidaridad en la protesta se manifestó en Polonia al principio de los años ochenta. La solidaridad de grupos que desarrollan sus propios intereses impera hoy en día en muchos países. Sin embargo, ya es tiempo de implantar una solidaridad basada en unos proyectos sociales comunes que establezcan fundamentos adecuados para construir unas mejores condiciones de vida para todos los miembros de la sociedad. El ajuste de cuentas con el pasado debe ser doloroso, pero como nadie es inocente, nadie tiene derecho moral a ejercer el papel de juez. Unos se dejaron sobornar, otros 
asesinaban y robaban, otros 'únicamente' se abstenían de protestar acomodándose y sacando provecho de situaciones oportunas, algunos luchaban respondiendo al mal con el mal, mientras los demás no reaccionaban, se quedaban quietos permitiendo que el mal se extendiera impunemente y erosionara el tejido social. Probablemente no existe compensación alguna que satisfaga a todos y ajuste las cuentas. Tal vez muchos de los que quieren crear nuevas condiciones sociales, lo hacen incitados por miedo, o porque quieren legalizar sus bienes obtenidos ilícitamente, o por otras razones moralmente dudosas. Sin embargo, se debe aprovechar cualquier ocasión para mejorar las vidas de los que forman la sociedad. No se puede justificar el mal, sino que hay que - como dijo Tischner- aprender a vencerlo, poner barreras para que no se extienda y no contestar con el mal por el mal. Hay que perdonar el mal, en los otros y en sí mismo, entender el bien y, apoyándonos en las amargas experiencias, construir las estructuras sociales de tal manera que rediman a las futuras generaciones de nuestros pecados. Porque la solidaridad significa no solo el sentido de comunidad con los que crean la sociedad, sino también con los que van a nacer y continuar la tarea que hemos empezado. Solo mirando hacia el futuro podremos entender la enseñanza que nos ha brindado el pasado. Solo esta perspectiva nos permite liberarnos de las ilusiones, aunque estas sean más atractivas pero imposibles de realizar, y al mismo tiempo poder hacer las transformaciones por el bien del mundo. Nos damos cuenta finalmente, que hay muchas tensiones de diversa naturaleza: económica, social, política, etc., que afectan las relaciones humanas alrededor del mundo. En este contexto, las ideas sobre solidaridad propuestas por el profesor J. Tischner, pueden ser extensibles y útiles más allá de la circunstancia específicas del movimiento de Solidarnośćen Polonia por esta misma razón.

\section{Bibliografia}

Hayek F. A., Droga do zniewolenia [Camino de servidumbre], tłum. K. Gurba, L. Klyszcz, J. Margański, D. Rodziewicz, Kraków 1996. 
Lavelle L., Traité de valeurs, Paris 1951.

Millon-Delsol Ch., Solidarność zakorzeniona [Una Solidaridad enraizada], “Znak” 2000 nr 543, p. 51-67.

Sztompka P., Zaufanie. Fundamenty społeczeństwa [Confianza. Los fundamentos de la sociedad], Kraków 2007.

Tischner J., Cierpkie winogrona i chytrość rozumu [Las uvas agrías y la malicia de la razón], “Znak” 1998 nr 8 (519), p. 34-41.

Tischner J., Filozofia człowieka dla duszpasterzy i artystów [La filosofía del hombre por los sacerdotes y artistas], Kraków 1991.

Tischner J., Filozofia dramatu [Filosofía del drama], Kraków 1998.

Tischner J., Ludzie z kryjówek [Los hombres de los escondites], [en:] Myślenie wedtug wartości, Kraków 1993.

Tischner J., Myślenie wedlug wartości [Un pensamiento de acuerdo a los valores], Kraków 1982.

Tischner J., Pomoc $w$ rachunku sumienia [Una guía para el examen de la conciencia], Kraków 2000.

Tischner J., Spór o istnienie człowieka [Controversia sobre la existencia del hombre], Kraków 1998.

Tischner J., Wybrane problemy filozofii człowieka [Algunos problemas de la filosofia del hombre], Kraków 1985. 